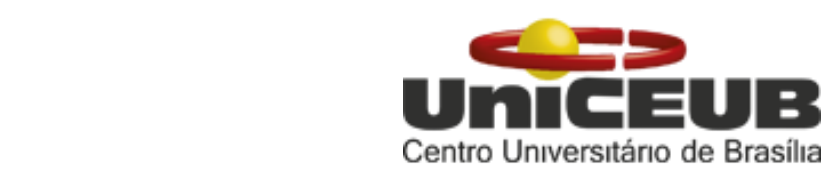

CENTRO UNIVERSITÁRIO DE BRASÍLIA - UniCEUB

PROGRAMA DE INICIAÇÃO CIENTÍFICA

ÂNGELO SANTANA GUERRA

A EFICÁCIA DO BLOQUEIO RADICULAR FORAMINAL NO ALÍVIO DA DOR CIÁTICA DEVIDO A HÉRNIA DISCAL LOMBAR: UM ESTUDO PROSPECTIVO, CONTROLADO, RANDOMIZADO E DUPLO-CEGO.

BRASÍLIA 


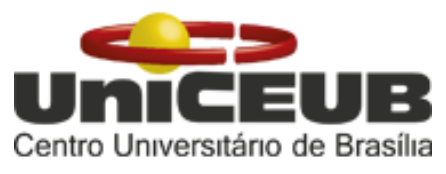

ÂNGELO SANTANA GUERRA

\section{A EFICÁCIA DO BLOQUEIO RADICULAR FORAMINAL NO ALÍVIO DA DOR CIÁTICA DEVIDO A HÉRNIA DISCAL LOMBAR: UM ESTUDO PROSPECTIVO, CONTROLADO, RANDOMIZADO E DUPLO-CEGO}

Relatório final de pesquisa de Iniciação Científica apresentado à Assessoria de Pós-Graduação e Pesquisa.

Orientação: Marcello Oliveira Barbosa

BRASÍLIA 


\section{RESUMO}

Objetivo: Avaliar o perfil clínico, a melhora da dor e a necessidade de intervenções cirúrgicas em pacientes submetidos ao bloqueio transforaminal com uso de corticosteroides. Métodos: Trata-se de estudo prospectivo, randomizado e duplo-cego, com $n=30$ com dor radicular unilateral em membros inferiores. Houve alocação aleatória dos pacientes em dois grupos, intervenção e controle. Foi procedida realização de bloqueio transforaminal com bupivacaína, dexametasona e clonidina no grupo intervenção, e no controle realizada com água destilada e bupivacaína. Além disso, foi aplicado o questionário de incapacidade de Oswestry. Resultados: No grupo intervenção houve alívio imediato da dor, mas após 3 semanas havia declínio desse efeito, conquanto que no grupo controle, o alívio álgico permaneceu (mesmo em menor escala). Discussão: alguns estudos atribuem a melhora aguda dos pacientes ao efeito do corticoide infiltrado, no entanto a utilização de anestésico no grupo controle, realizado neste estudo, demonstrou que esta melhora aguda pode ser atribuída ao anestésico utilizado e não ao corticoide. Conclusões: Novos estudos com um espaço amostral maior e um seguimento mais prolongado são necessários para validar as hipóteses aventadas.

Palavras-Chave: hérnia de disco lombar; bloqueio foraminal; dor ciática 


\section{SUMÁRIO}

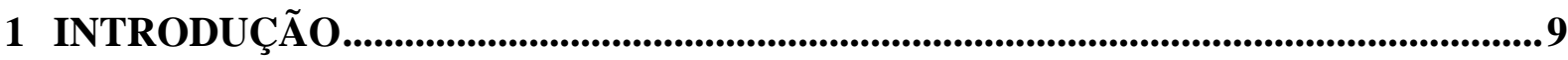

2 FUNDAMENTAÇÃO TEÓRICA .................................................................................10

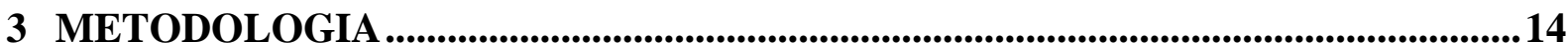

4 RESULTADOS E DISCUSSÃO............................................................................ 18

5 CONSIDERAÇÕES FINAIS ................................................... Erro! Indicador não definido.

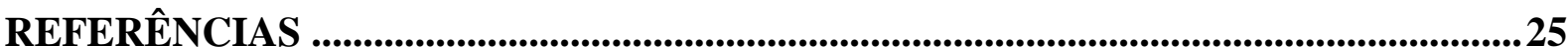

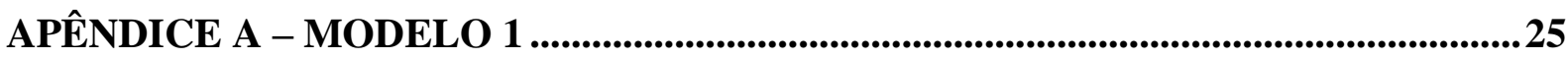

ANEXO A - EXEMPLO DE QUESTIONÁRIO .....................................................................26 


\section{INTRODUÇÃO}

A hérnia de disco é causada pela ruptura do anel fibroso, com o subsequente deslocamento da massa do centro do disco nos espaços intervertebrais. ${ }^{1}$ Parte do núcleo pulposo, placa terminal cartilaginosa, osso fragmentado ou tecido anular fragmentado são deslocados para fora do espaço discal. ${ }^{2}$

A manifestação clínica ocorrerá a depender do volume de material herniado, devido à compressão e irritação das raízes lombares e do saco dural. A sintomatologia típica da doença é representada por uma lombalgia inicial, que pode evoluir para lombociatalgia (em geral, após uma semana) e, finalmente, persistir como ciática pura. ${ }^{3,4,5}$

Dentre as alterações degenerativas da coluna lombar, a hérnia discal lombar é o diagnóstico mais comum, a maior causa de aposentadoria por invalidez no Brasil segundo o INSS e o que mais leva à necessidade de intervenção cirúrgica. ${ }^{3,4,6}$ Apesar de ser descrita nas mais variadas faixas etárias, a hérnia discal ocorre principalmente entre a 4 a e a 5 a décadas de vida. ${ }^{4,5}$

Um exame físico adequado é essencial para o diagnóstico, podendo inclusive, através de cuidadosa avaliação dos dermátomos e miótomos, determinar o espaço vertebral em que está localizada a hérnia ${ }^{4}$. Exames de imagem também são fundamentais para o diagnóstico, localização, classificação e prognóstico da doença. ${ }^{3}$ A ressonância magnética (RM) é considerada padrão-ouro para o diagnóstico, sendo indispensável para a correta avaliação do paciente, visto que permite a obtenção de informações detalhadas de partes ósseas e de tecidos moles que podem ajudar não só no diagnóstico correto, mas até na proposta terapêutica. $^{3}$

Com relação à terapêutica instituída, diversas técnicas são descritas na literatura, porém atualmente priorizam-se os procedimentos cirúrgicos minimamente invasivos, devido a menor agressão tecidual gerada, o menor tempo de internação, os menores riscos anestésicos e o retorno precoce às atividades laborais. ${ }^{7,4}$ 
Os bloqueios transforaminal e epidural guiados por radioscopia são procedimentos amplamente empregados e consistem em boas opções entre as técnicas minimamente invasivas no tratamento da hérnia de disco lombar. ${ }^{7,4}$ Com a associação de contrastes radiopacos nas infiltrações, obteve-se maior precisão na localização da raiz nervosa. No entanto, apesar do desenvolvimento e amplo emprego dessa técnica, existem muitas divergências a respeito da melhora clínica após utilização desta associada a corticosteroides como modalidade terapêutica. ${ }^{8}$

Como exposto, a hérnia de disco lombar é um assunto de importante discussão na atualidade. O objetivo deste trabalho é avaliar o perfil clínico, a melhora da dor e a necessidade de intervenções cirúrgicas em pacientes submetidos a essas técnicas minimamente invasivas, especialmente o bloqueio transforaminal com uso de corticosteroides.

\section{FUNDAMENTAÇÃO TEÓRICA}

A dor lombar e ciática afetam a maioria da população em pelo menos um episódio durante a vida. Entretanto, a história natural da hérnia de disco lombar é favorável e em geral, há melhora espontânea dos sintomas ou após instituição de terapia conservadora ${ }^{13}$.

A hérnia de disco é causada pela ruptura do anel fibroso, com o subsequente deslocamento da massa do centro do disco nos espaços intervertebrais ${ }^{10}$. Parte do núcleo pulposo, placa terminal cartilaginosa, osso fragmentado ou tecido anular fragmentado são deslocados para fora do espaço discal ${ }^{15}$. Essas hérnias variam com relação à localização na coluna vertebral, podendo ser cervicais, torácicas, lombares e sacrais ${ }^{15}$.

Pondera-se que $2 \%$ a $3 \%$ da população tenham diagnóstico de hérnia de disco lombar, com prevalência em pessoas acima de 35 anos de 4,8\% em homens e 2,5\% em mulheres. Ademais, representa o diagnóstico mais comum dentre as alterações degenerativas da coluna lombar e a principal causa de cirurgia da coluna ${ }^{5}$.

Sobre a história natural da doença discal, o processo degenerativo é divido em três estágios. O primeiro estágio é a disfunção, que é encontrado em indivíduos entre 15 e 45 
anos, e é caracterizado por injúrias radiais e circunferenciais no anel discal e sinovite localizada nas articulações facetárias. O segundo é a instabilidade, ocorre em pessoas entre 35 e 70 anos, caracteriza-se por ruptura interna do disco, reabsorção progressiva do disco, degeneração das articulações facetárias com frouxidão capsular, subluxação e erosão articular. O estágio final, presente em pacientes com mais de 60 anos, é a estabilização, e nele o progressivo desenvolvimento de osso hipertrófico ao redor do disco e articulações facetárias levam ao enrijecimento segmentar ou anquilose franca ${ }^{18}$. A hérnia de disco é considerada uma complicação da degeneração discal nos estágios de disfunção e instabilidade.

Evidências apontam para a participação da herança genética como componente importante na etiopatogênese da hérnia de disco. Há diversos estudos buscando identificar genes que desempenham papel relevante no desenvolvimento e evolução dessa enfermidade ${ }^{19}$. Dentre os possíveis envolvidos parecem figurar o gene receptor da vitamina D (gene VDR), o gene que codifica para uma das cadeias polipeptídicas do colágeno IX (o gene COL9A2) e o gene "aggrecan" humano (AGC), responsável pela codificação do proteoglicano, maior componente proteico da cartilagem estrutural, que suporta a função biomecânica nesse tecido.

Sabe-se que a dor na hérnia discal lombar resulta da soma de componentes mecânicos e inflamatórios, isso devido à herniação, degeneração do disco e da estenose foraminal ou do canal medular ${ }^{6}$. Com relação às manifestações clínicas da hérnia lombar, a dor lombar é a principal manifestação e envolve três tipos: a baixa, que é localizada entre o último arco costal e a prega glútea e de origem biomecânica; a lombociatalgia, que é irradiada da região lombar até um ou ambos os membros inferiores devido à irritação de raiz nervosa ou exacerbação de sintomas crônicos; e a ciática, uni ou bilateral, irradiada na maioria das vezes, da raiz da coxa, atravessando o joelho, até o pé ipsilateral. Podem estar presentes ou não o déficit sensitivo e/ou motor $^{7}$.

O processo inflamatório e o fragmento do disco intervertebral adjacente à raiz nervosa lombar geram a lombociatalgia, que piora ao permanecer sentado e/ou de pé por 
período prolongado ou após tosse e pode ser identificada pelo dermátomo correspondente à raiz nervosa envolvida ${ }^{14}$.

O diagnóstico da hérnia discal lombar deve ser suspeitado pelo exame físico e história clínica. Um exame físico adequado é essencial para o diagnóstico, podendo inclusive, através da cuidadosa avaliação dos dermátomos e miótomos, determinar o espaço intervertebral em que está localizada a hérnia ${ }^{4}$. A presença de ciática é um indicador de alto valor preditivo para hérnia de disco (sensibilidade de 0,95; especificidade de 0,88; valor preditivo positivo de 7,9 e valor preditivo negativo de 0,06$)$. Outro sinal altamente específico de hérnia de disco é o sinal de Laségue contralateral, que quando positivo tem a alta especificidade de 0,4 , porém com baixa sensibilidade ${ }^{17}$. Esse sinal pode ser obtido pelo teste de elevação da perna retificada com o paciente em decúbito dorsal, que é o principal teste realizado no exame físico para diagnóstico da hérnia discal lombar e avaliação da progressão da doença ${ }^{23}$. Ademais, há também o teste de Nachlas, que consiste no posicionamento do paciente em decúbito ventral e subsequente extensão do quadril com o joelho em flexão passiva até que o calcanhar toque a nádega. $\mathrm{O}$ aparecimento de dor na região lombar pode indicar compressão da raiz L2-L324.

Exames de imagem são fundamentais para o diagnóstico, localização, classificação e prognóstico da doença. A radiografia tem importância limitada no diagnóstico em si, mas é de extrema importância para afastar possíveis comorbidades associadas como infecções, tumores e outras anormalidades que evoluem com sintomatologia similar ${ }^{4}$. A tomografia computadorizada axial ainda é bastante utilizada no Brasil. No entanto, apesar desse exame ser capaz de identificar a hérnia discal, não se aproxima da qualidade e sensibilidade que a ressonância magnética oferece ${ }^{4}$.

A ressonância magnética é, atualmente, o exame padrão ouro para diagnóstico de hérnia discal. Além de possibilitar a visualização da herniação em si esse exame permite uma melhor avaliação da localização do disco herniado, de possíveis alterações degenerativas do disco vertebral, integridade de estruturas nervosas como o trajeto do nervo através do forame e informações detalhadas de partes ósseas e de tecidos moles. Dessa forma, a ressonância magnética é indispensável para a elaboração de uma proposta terapêutica ${ }^{4,18}$. 
De acordo com a ressonância magnética a hérnia pode ser classificada conforme a forma do disco herniado. Essa descrição morfológica se dá a partir do deslocamento do núcleo pulposo em relação aos limites intervertebrais que pode formar três diferentes formas: protrusão, extrusão ou sequestro. A protrusão ocorre quando a distância da altura da herniação (no corte axial) é menor que a distância da base da região herniada em qualquer um dos planos. A extrusão ocorre quando a distância da base da região herniada é menor que a altura da hérnia. O sequestro ocorre quando há uma descontinuidade entre o material herniado e o disco intervertebral ${ }^{4}$.

Com relação à terapêutica instituída, existem diversas técnicas descritas na literatura que abrangem o tratamento conservador, as técnicas minimamente invasivas e os procedimentos cirúrgicos. Atualmente tem-se dado prioridade aos tratamentos conservadores e às técnicas minimamente invasivas como escolhas terapêuticas iniciais, sendo a cirurgia um tratamento de exceção para os casos de insucesso do tratamento inicial $^{1,5,10}$.

O tratamento conservador consiste na imobilização da região lombar do paciente de maneira parcial ou completa em associação a outros tratamentos adjuvantes como uso de cintos e coletes, manipulação, fisioterapia, tração, crioterapia, acupuntura e o uso de analgésicos e anti-inflamatórios ${ }^{10}$. Com relação às técnicas minimamente invasivas, os bloqueios transforaminal e epidural têm sido terapêuticas bastante eficazes do tratamento da dor e reabilitação laboral dos pacientes com hérnia de disco lombar ${ }^{5}$. Este tratamento consiste, em resumo, na aplicação de corticosteroides (geralmente a metilprednisolona) com soro fisiológico ou corticosteroide com levobupivaracaína no espaço epidural ou através do forame diretamente nas raízes nervosas ${ }^{7}$.

A técnica utilizada no bloqueio transforaminal deve ser realizada da seguinte maneira: o paciente posicionado em decúbito ventral com um travesseiro sob o abdome. Um aparelho de fluoroscopia deve ser utilizado para obter a imagem anteroposterior e poder identificar o nível desejado da coluna, seguido por um ângulo oblíquo ipsilateral Scotty-Dog. A posição das seis horas do pedículo é marcada e infiltrada com lidocaína. Uma 
agulha Tuohy deve ser dirigida para coluna vertebral sob orientação fluoroscópica intermitente nos forames neurais, de tal modo que a sua ponta fique no triângulo formado pela raiz do nervo, medialmente, o pedículo ósseo, superiormente, e a margem lateral do forame, lateralmente. É injetado o contraste radiopaco e a posição correta da agulha é confirmada pela observação do fluxo do contraste injetado através da bainha nervosa em cada nível desenhando a raiz correspondente. Uma vez confirmada a colocação e o desenho da raiz nervosa, deve ser injetada a medicação de escolha ${ }^{5}$.

O tratamento cirúrgico visa à descompressão das estruturas nervosas ${ }^{4}$. A discectomia tradicional ainda é um procedimento utilizado, no entanto, técnicas menos invasivas como a microdiscectomia tem tido resultados melhores que os procedimentos que visam à retirada agressiva do disco. Isso é evidenciado pelo menor tempo cirúrgico, sangramento reduzido durante o procedimento, alívio eficaz dos sintomas, menor taxa de complicações nos 10 anos seguintes de seguimento ${ }^{4}$.

As indicações absolutas de tratamento cirúrgico são síndrome da cauda equina e paresia importante. A indicações relativas são: ciática que não responde ao tratamento conservador por, no mínimo, seis semanas, déficit motor com força motora menor que o grau 3 e ciática por mais de seis semanas ou dor articular associada à estenose óssea foraminal ${ }^{4}$.

\section{METODOLOGIA}

Foram avaliados 30 pacientes com dor radicular unilateral em membros inferiores, todos com resultado de ressonância magnética lombar evidenciando hérnia de disco lombar em apenas um segmento, por meio de estudo prospectivo, randomizado e duplo-cego. Todos os pacientes assinaram Termo de Consentimento Informado Livre Esclarecido, contendo os riscos e benefícios da terapia instituída.

Os pacientes foram divididos em dois grupos escolhidos aleatoriamente por meio de lançamento de moedas, aqueles que tiveram como resultado "cara" foram alocados no 
grupo 1 (intervenção) e aqueles que tiveram como resultado "coroa" foram alocados no grupo 2 (controle). O trabalho foi aprovado pelo Comitê Nacional de Ética e Pesquisa (CONEP) sob o número 3.104.615/18 - disponível na Plataforma Brasil.

Foram considerados critérios de exclusão a presença de outras doenças que fazem diagnóstico diferencial com a hérnia discal lombar cuja dor é semelhante à da hérnia, como a bursite trocantérica e/ou tendinite glúteas, coxartrose, pacientes que já tenham realizado bloqueio foraminal e/ou epidural nos últimos 3 anos, pacientes já submetidos a procedimento cirúrgico discal prévio (microdiscectomia, discectomia aberta ou artrodese), presença de tumoração (neoplasia) na região lombar e/ou infecção com compressão radicular relacionada, litíase renal documentada e paciente em uso de anticoagulantes e antiagregantes plaquetários.

Na técnica realizada, o paciente era posicionado em decúbito ventral horizontal, com apoio (travesseiro) sob abdome, quadris e joelhos semi-fletidos a aproximadamente 30 graus. Os parâmetros vitais eram monitorizados. Após assepsia e colocação de campos estéreis eram realizados exames de imagem com radioscopia. Primeiramente, o nível a ser infiltrado era determinado com realização da incidência ântero-posterior absoluta. De acordo com o nível, muitas vezes foi necessário realizar a incidência descrita por Ferguson, de angulação cranial da radioscopia, principalmente no nível L5-S1. Uma vez que se visualizava a placa terminal como uma linha única, sem duplo contorno, o radioscópio era rodado para o lado acometido, gerando uma imagem oblíqua do lado invertido. Geralmente entre 20 e 25 graus eram suficientes para se obter uma correta incidência, determinando uma correta região anatômica dos pedículos e facetas articulares. O posicionamento do paciente era mantido e a angulação no plano craniocaudal com relação à angulação era anotado pelo técnico em radioscopia. Um fórceps Kelly reto era apoiado sob a região lombar do paciente para estabelecer o alvo exato, utilizando-se, assim, a ponta do instrumento que era mobilizada até coincidir exatamente com o alvo da imagem correspondente à região inferior do pedículo com leve desvio medial. Uma infiltração local do alvo com lidocaína $2 \%$ era realizada, então a agulha espinhal 22 Gauges e com 3,5 polegadas de comprimento com ponta de Quincke era introduzida. A agulha era então introduzida, seguindo a técnica 
coaxial, e observada como um único ponto ao seguir o mesmo trajeto de incidência na radioscopia (Figura 1 ).

Figura 1. Raiz nervosa delineada por contraste, visualizada na radioscopia.

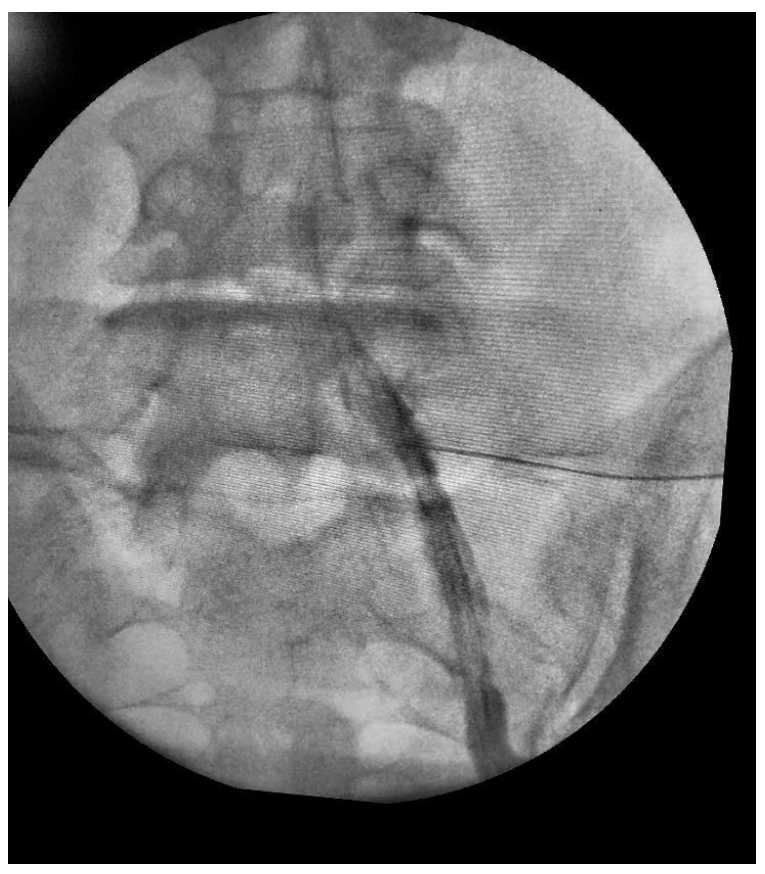

Conforme a agulha era introduzida a posição da radioscopia era alterada para fornecer a incidência de perfil absoluto, então a profundidade da agulha era controlada, principalmente na região do forame intervertebral. Próximo à porção inferior do pedículo, o radioscópio retornava para a posição oblíqua ou ântero-posterior absoluta. Injetava-se o contraste não iônico sob visão contínua da radioscopia para acompanhar a distribuição do contraste no espaço epidural e proteger de sua introdução no meio intravascular. Uma vez obtida uma distribuição adequada, injetava-se a solução. No caso do forame de L5-S1, uma visão ântero-posterior era realizada e a agulha posicionada no quadrante superior externo do forame, com a técnica da visão em túnel, assim o perfil era acompanhado até atingir a posição do forame. Após o procedimento, o paciente era encaminhado para recuperação pós-anestésica e permanecia em observação por aproximadamente 30 minutos. Nenhuma medicação era prescrita depois do procedimento.

Foram realizados os bloqueios nos forames alvo utilizando a solução de 01 (um) ml do anestésico local bupivacaína a 0,5\% misturado a 02 (dois) $\mathrm{ml}$ de dexametasona 2,5 
$\mathrm{ml} / 10 \mathrm{mg}$ e 01 (um) $\mathrm{ml}$ de clonidina $150 \mathrm{mcg} / \mathrm{ml}$ nos pacientes do grupo 1 (intervenção). No grupo 2 (controle) foi realizado o bloqueio no forame alvo utilizando 03 (três) $\mathrm{ml}$ de água destilada e 01 (um) $\mathrm{ml}$ de bupivacaína a 0,5\%. O estudo foi duplo-cego, isto é, os médicos não souberam o que estava sendo injetado e os pacientes não sabiam a que grupo pertenciam. Todos os quatro líquidos (água destilada, dexametasona, bupivacaína e clonidina) são transparentes, inclusive quando administrados na mesma seringa. Todos os bloqueios foram realizados em salas do centro cirúrgico do Hospital Regional do Paranoá (HRPa), centro de referência em coluna do DF, usando agulha de raquianestesia de $22 \mathrm{G} \times 10$ $\mathrm{cm}$ e o intensificador de imagens para determinar o correto posicionamento da agulha no forame intervertebral. Cada seringa foi preparada por um pesquisador externo, de acordo com o critério de randomização já citado, e entregue ao médico responsável pelo procedimento sem que ele saiba o conteúdo.

Foi aplicado questionário simplificado de incapacidade de Oswestry traduzido para o português em 3 oportunidades para cada paciente: pré-bloqueio (Q1), uma semana após o bloqueio (Q2) e três semanas após o bloqueio (Q3). Nesse questionário os pacientes deveriam responder a dez perguntas, sendo que para cada pergunta havia uma pontuação de 0 a 5 pontos. As dez perguntas eram referentes a intensidade da dor, cuidados pessoais, dificuldade para carregar pesos, andar, sentar-se e ficar de pé, alterações no sono, vida sexual, vida social e incapacidade de viajar. A pontuação foi convertida para porcentagem, sendo que quanto mais próximo a $100 \%$ maior a incapacidade do paciente, e quanto mais próxima de $0 \%$ menor a incapacidade do paciente. Todos os questionários foram aplicados pela mesma pessoa.

Foram reunidas informações gerais, tais como idade, sexo, tratamentos clínicos adjuvantes realizados previamente, raiz nervosa bloqueada, ocupação, influência da doença na ocupação e por fim, a necessidade ou não de intervenção cirúrgica após a realização do bloqueio.

Os dados obtidos na pesquisa foram compilados e dispostos de maneira expositiva, com comparação intra e intergrupos. Ademais, os resultados foram comparados aos disponíveis em outros estudos de desenho semelhante. 


\section{RESULTADOS E DISCUSSÃO}

\section{Resultados}

A amostra da pesquisa consistiu em 30 pacientes, sendo $60 \%(n=18)$ do sexo feminino, com idade média de 47,7 anos $( \pm 9,3)$. O grupo da intervenção constitui-se por 16 pacientes, sendo que sua maioria era do sexo feminino (62,5\%), com média de 46,1 anos $( \pm 9,1)$. Já o grupo controle foi composto por 14 pacientes, com maioria do gênero feminino $(57,1 \%)$ e média de idade de 49,5 anos $( \pm 9,6)$.

Com relação à execução laboral, 28 indivíduos possuíam emprego, sendo que destes, 21 abandonaram a profissão devido à doença. Sete desses pacientes persistiram trabalhando, entretanto, referiram que a comorbidade atrapalha de alguma forma em sua atividade laboral. Apenas dois já eram desempregados. Quanto às profissões exercidas, as mais frequentes foram empregados domésticos $(26,7 \%)$ e pedreiro/servente $(16,7 \%)$.

Tabela 1. Distribuição quanto à ocupação dos pacientes que fizeram parte da pesquisa

\begin{tabular}{|l|l|l|}
\hline Ocupação & N & $\begin{array}{l}\text { Interrupção do } \\
\text { trabalho devido } \\
\text { doença (n) }\end{array}$ \\
\hline Empregado doméstico & 8 & 5 \\
\hline Pedreiro/servente & 5 & 5 \\
\hline Serviços gerais & 2 & 1 \\
\hline Atendente & 2 & 2 \\
\hline Comerciante & 1 & - \\
\hline Cuidadora de idosos & 1 & - \\
\hline Carpinteiro & 1 & 1 \\
\hline Marmoraria & 1 & 1 \\
\hline
\end{tabular}




\begin{tabular}{|l|l|l|}
\hline Polidor de carro & 1 & 1 \\
\hline Cabeleireiro & 1 & 1 \\
\hline Agricultor & 1 & 1 \\
\hline Técnico de enfermagem & 1 & 1 \\
\hline Motorista & 1 & 1 \\
\hline Lavanderia & 1 & 1 \\
\hline Técnico de laboratório & 1 & 1 \\
\hline
\end{tabular}

Sobre a realização de tratamentos adjuvantes realizados em até 18 meses anteriores à pesquisa, sem melhora efetiva, 24 pacientes $(80 \%)$ foram submetidos a pelo menos um tipo de procedimento. Dentre os tratamentos pesquisados estavam fisioterapia, hidroterapia e acupuntura. No grupo intervenção os dados foram dispostos da seguinte maneira: $62,5 \%$ realizaram fisioterapia, $25 \%$ hidroterapia, acupuntura $31,3 \%, 12,5 \%$ realizaram os três procedimentos e 31,3\% não realizou nenhum tratamento adjuvante. Já em pacientes controle, houve a seguinte distribuição: 92,9\% realizou fisioterapia, 35,7\% acupuntura, $14,3 \%$ hidroterapia, $14,3 \%$ os três tratamentos e $7,1 \%$ não realizou tratamento adjuvante.

Quanto à localização da raiz nervosa a ser bloqueada, na amostra como um todo, houve prevalência do nível L5-S1 (46,7\%), seguido por L4-L5 (30\%), S1 (13,3\%). A distribuição conforme os grupos intervenção e controle está disposta nos gráficos 1 e 2 .

Tabela 2. Distribuição dos pacientes de acordo com idades, gênero, realização de tratamentos adjuvantes e raiz nervosa bloqueada.

\begin{tabular}{ll|l|l|} 
Intervenção $(n=$ & Controle $(n=14)$ & Total $(n=30)$
\end{tabular}




\begin{tabular}{|c|c|c|c|c|}
\hline & 16) & & \\
\hline \multicolumn{2}{|l|}{ Idade (média) } & 46,1 & 49,5 & 47,7 \\
\hline \multicolumn{2}{|c|}{ Gênero feminino } & $10(62,5 \%)$ & $8(57,1 \%)$ & $18(60 \%)$ \\
\hline \multicolumn{2}{|c|}{$\begin{array}{l}\text { Submetido a tratamento } \\
\text { adjuvante }\end{array}$} & $11(68,8 \%)$ & $13(92,9 \%)$ & 24 (80\%) \\
\hline \multirow[t]{2}{*}{ Raiz nervosa } & L4-L5 & $4(25 \%)$ & $5(35,7 \%)$ & $9(30 \%)$ \\
\hline & L5-S1 & $8(50 \%)$ & $6(42,9 \%)$ & $14(46,7 \%)$ \\
\hline
\end{tabular}

Gráfico 1. Análise comparativa entre os grupos intervenção e controle quanto à variação na pontuação dos questionários pré bloqueio e uma semana após.

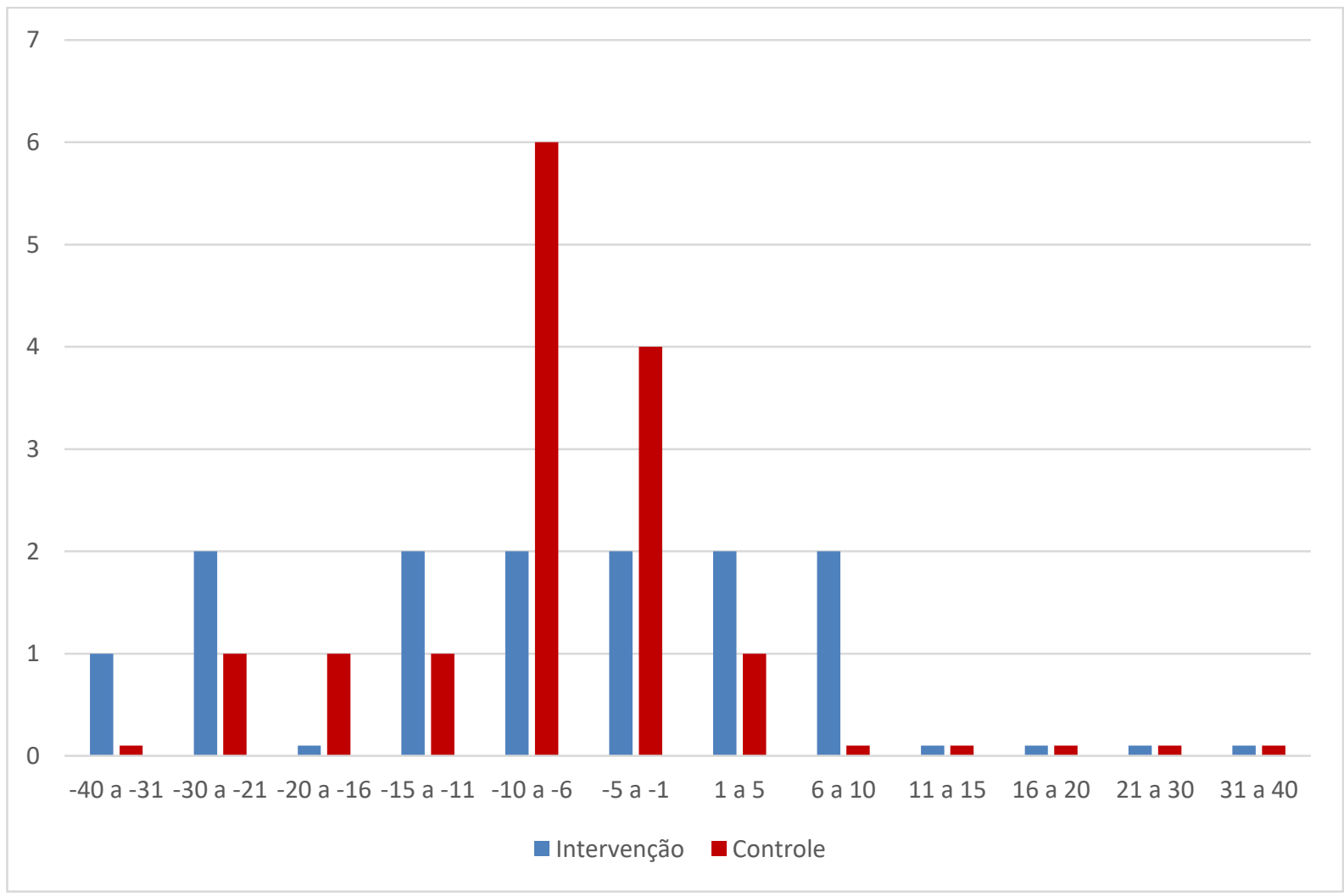

Gráfico 2. Análise comparativa entre os grupos intervenção e controle quanto à variação na pontuação dos questionários pré bloqueio e três semanas após. 


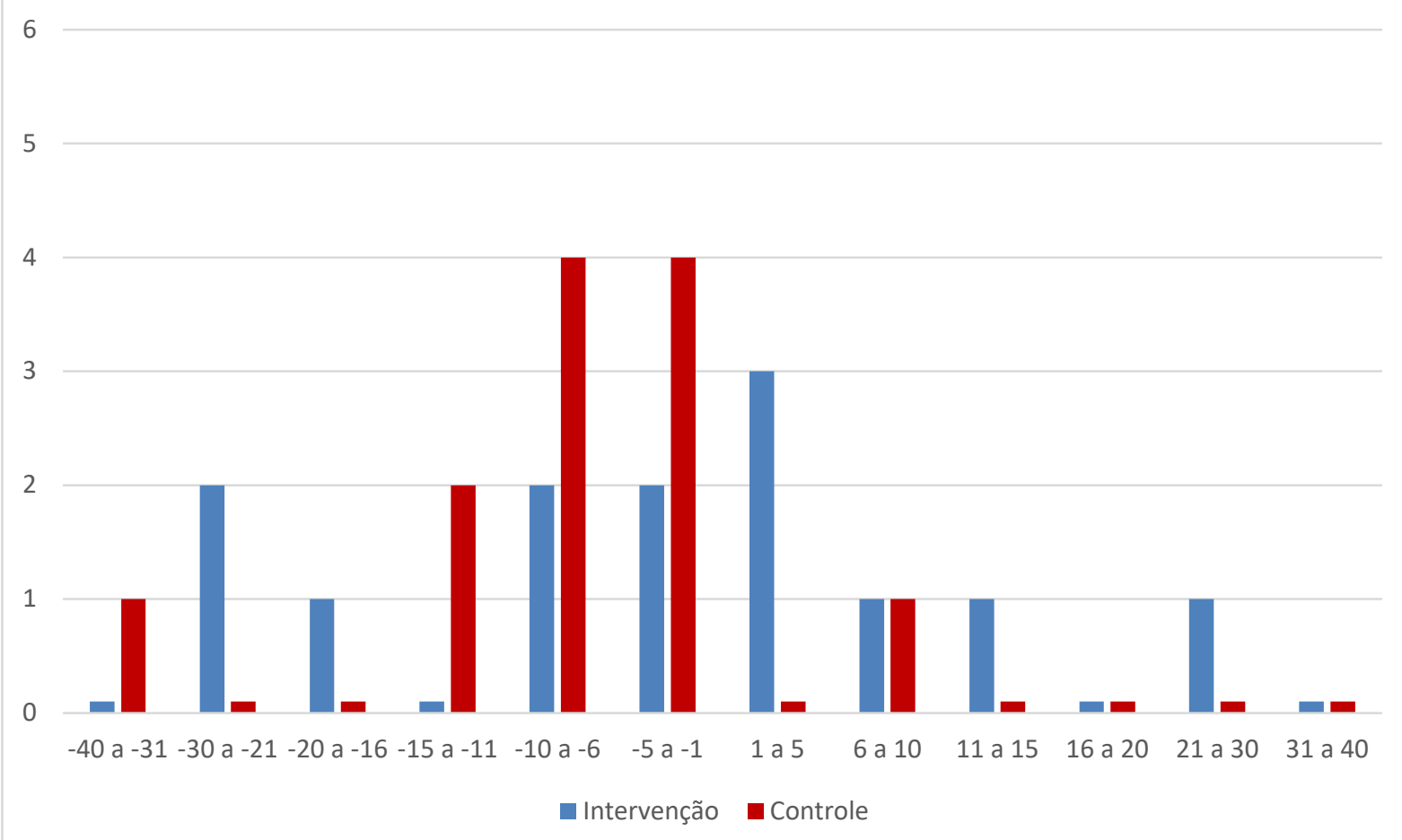

Gráfico 3. Análise comparativa entre os grupos intervenção e controle quanto às médias em porcentagem dos questionários pré bloqueio, 1 semana após e 3 semanas após.

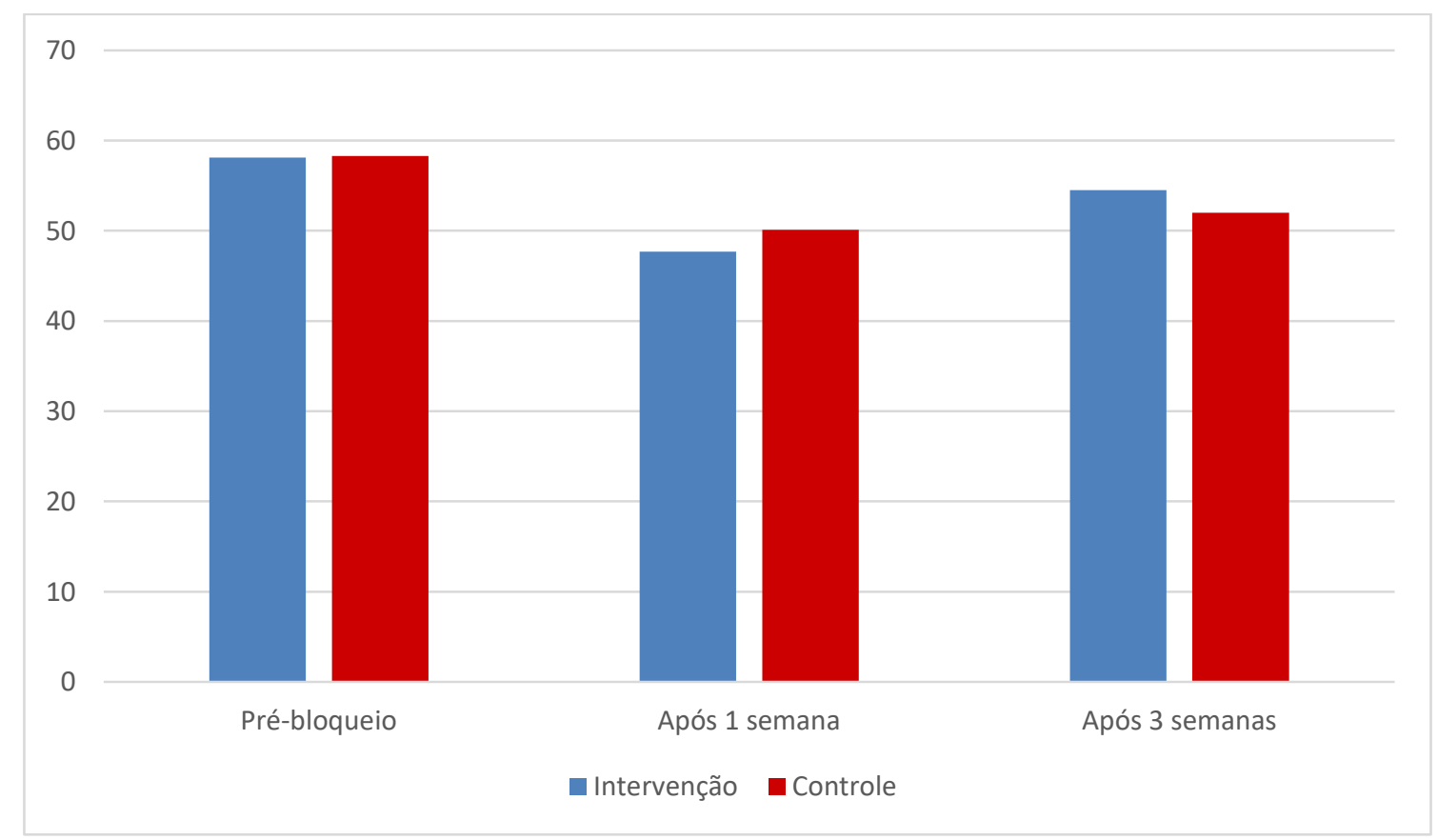

Quanto a aplicação do índice de Oswestry na situação pré bloqueio, os 30 pacientes da amostra apresentaram média de pontuação de 58,2 ( $\pm 16,5)$. No grupo intervenção a média foi de 58,1 ( \pm 16 ), enquanto que nos controles foi de $58,3( \pm 17,7)$. Em três pacientes 
do grupo intervenção, não foi possível a aplicação de Q2 e Q3, visto que houve intervenção cirúrgica em menos de uma semana após o bloqueio, logo estes pacientes foram excluídos das análises estatísticas.

O grupo 1 apresentou sete pacientes com melhora $(13,7)$ no questionário, ao se comparar pontuação no questionário Q1 e Q3. Um n= 6 apresentou piora (8,7). Comparando o grupo com um todo, houve pontuação média de 58,1\% em Q1, 47,7\% em Q2 e 54,5\% em Q3.

O grupo 2 apresentou 11 pacientes com melhora $(9,0)$ e apenas um com piora (média $=10$ ) ao se comparar pontuação no questionário Q1 e Q3. Dois pacientes persistiram sem alterações na pontuação do questionário. Comparando o grupo controle como um todo, houve pontuação média de 58,3\% em Q1, 50,1\% em Q2 e 52\% em Q3.

\section{Discussão}

Neste estudo foi evidenciado que pacientes submetidos a bloqueio transforaminal com injeção de corticoide e anestésico apresentam alívio imediato, mas que após três semanas, esse efeito não perdura, com o paciente não demonstrando melhora perceptível. Já no grupo controle, houve alívio álgico após uma semana que permaneceu, mesmo que em menor escala, após 3 semanas.

Em estudo de Souza et $a l^{8}{ }^{8}$, foi realizado bloqueio foraminal em 61 pacientes sendo 32 pacientes com anestésico e corticoide e 29 apenas com solução salina. Pôde-se observar melhora estatisticamente significativa do grupo que recebeu a medicação em relação ao grupo controle após uma semana pela escala de dor e após 3 meses quando utilizado o questionário de Oswestry. Quando comparamos ao nosso estudo, em que no grupo controle 
foi utilizado anestésico com água destilada e os pacientes obtiveram melhora semelhante ao grupo que recebeu corticoide, podemos inferir que essa melhora, na primeira semana, provavelmente ocorre pelo efeito do anestésico. A melhora observada após 3 meses no questionário de Oswestry indica que o período de seguimento da pesquisa deve ser estendido a pelo menos três meses para que tenhamos resultados mais precisos.

Karppinen et $a l^{9}{ }^{9}$ em estudo duplo-cego envolvendo 160 pacientes com ciática unilateral realizou infiltração peri-radicular com corticoide e anestésico em um dos grupos e solução salina no outro grupo. Nos resultados publicados, pode-se observar que o grupo que recebeu medicação obteve melhora expressiva a curto prazo em relação ao controle, no entanto após 3 meses essa melhora deixou de ser evidente. Esse resultado quando comparado ao de nosso trabalho, favorece a possibilidade de que a melhora nas primeiras semanas está relacionada ao uso de anestésico na solução e não do corticoide.

A hérnia de disco lombar é condição frequentemente relatada em pacientes entre 40 a 50 anos, com prevalência maior em homens. ${ }^{3}$ No presente estudo foi evidenciado uma amostra com média de 47,7 anos e com a maioria dos pacientes sendo do sexo feminino (60\%). O parâmetro idade converge com o que há descrito em literatura, conquanto que no trabalho foi evidenciado uma maioria de mulheres na amostra, podendo sugerir um perfil populacional para o espaço amostral. Em estudo de Rezende et al. ${ }^{4}$, com $\mathrm{n}$ de 40 pacientes, foi evidenciado uma maioria de mulheres $(65 \%)$ na realização do bloqueio transforaminal.

No trabalho de Cardoso et $a .^{10}$ sobre associação do diagnóstico clínico com a ocupação em um serviço de fisioterapia foi observado como grupo de maior prevalência de 
hérnia de disco o grupo correspondente a serviços domésticos, assim como encontrado em nossa pesquisa. No entanto, o grupo construção civil não mostrou relação com o diagnóstico de hérnia de disco.

Fisher et al. ${ }^{11}$ em estudo sobre avaliação dos resultados de tratamento cirúrgico em pacientes com hérnia de disco lombar apresentando dor ciática, observou 82 pacientes sendo que o seguimento da hérnia eram dispostos da seguinte forma: L5-S1 (50\%), L4-L5 (46,3\%), L3-L4 (1,2\%) e L2-L3 (2,4\%). Dados estes semelhantes aos observados em nosso estudo.

\section{CONCLUSÃO}

Os resultados do nosso estudo sugerem um efeito positivo após uma semana do bloqueio foraminal tanto com a solução contendo corticoide e anestésico quanto com a solução contendo água destilada e anestésico. Após 3 semanas, no entanto, a solução contendo corticoide e anestésico não apresentou melhora efetiva, ao passo que os bloqueios com água destilada e anestésico continuaram apresentando alguma melhora.

Outros estudos com desenho semelhante a este apresentaram desfecho favorável ao grupo intervenção em curtos períodos, no entanto estes estudos, utilizaram apenas solução salina no grupo controle e, em sua grande maioria, não eram duplo-cegos, o que pode ter resultado no desfecho favorável do grupo intervenção em relação ao grupo controle.

O presente estudo apresenta algumas limitações como a reduzida amostra e o seguimento por período reduzido dos pacientes. Novos estudos com um espaço amostral maior e um seguimento mais prolongado são necessários para validar as hipóteses aventadas. 


\section{REFERÊNCIAS}

1- NEGRELLI, W.F. Hérnia discal: procedimentos de tratamento. Acta ortop bras. 9(4) out/dez, 2001.

2- SINGH, J.R.; CARDOZO, E.; CHRISTOLIAS, G.C. The clinical efficacy for twolevel transforaminal epidural steroid injections. PM R. 2017 Apr;9(4):377-382. doi: 10.1016/j.pmrj.2016.08.030. Epub 2016 Sep 7.

3- VIALLE, L.R.; et al. Hérnia discal lombar. Rev Bras Ortop. 2010;45(1):17-22.

4- REZENDE, R.; et al. Comparação da eficácia das técnicas transforaminal e interlaminar de bloqueio radicular feito no tratamento de hérnia de disco lombar. Rev Bras Ortop. 2015;50(2):220-225.

5- CARVALHO, L.B.; OYAKAWA, A.; et al. Hérnia de disco lombar: tratamento. Associação Brasileira de Medicina Física e Reabilitação; Sociedade Brasileira de Neurofisiologia Clínica. Acta Fisiatr. 2013;20(2):75-82.

6- Acompanhamento Mensal dos Benefícios Auxílios-Doença Previdenciários Concedidos segundo os Códigos da CID-10 - Janeiro a Dezembro de 2017. Acesso em abril de 2018. Disponível em: http://www.previdencia.gov.br/wpcontent/uploads/2018/03/AuxilioDoen\%C3\%A7a-Previdenciario_2017_completo_CID.pdf.

7- BARCELLOS ZANON, I. et al. Comparison of the effectiveness of radicular blocking techniques in the treatment of lumbar disk hernia. Coluna/Columna, v. 14, n. 4, p. 295-298, 2015.

8- SOUZA, F.F.R; NICOLAU, R.J.; LONGO, D.M.; RODRIGUES, L.M. Estudo clínico da eficácia do bloqueio anestésico radicular transforaminal no tratamento da radiculopatia lombar. Coluna/Columna. 2011; 10(3): 234-8. 
9- Karppinen J, Malmivaara A, Kurunlahti M, Kyllönen E, Pienimäki T, Nieminen P, et al. Peri-radicular infiltration for sciatica: a randomized controlled trial. Spine (Phila Pa 1976). 2001. May 1;26(9):1059-67.

10-CARDOSO, V.F; Pizzol, R.J.; Takamoto, P.M.; Gobbo, L.A.; Almeida, A.L.J. Associação do diagnóstico clínico com a situação ocupacional de usuários de um serviço de fisioterapia. Fisioter Pesqui. 2017;24(2):169-175.

11-FISHER, C. et al. Outcome evaluation of the operative management of lumbar disc herniation causing sciatica. J Neurosurg (Spine 4) 100:317-324, 2004.

ANEXO A - Questionário de Oswestry:

Seção 1: Intensidade da dor.

\begin{tabular}{|l|l|}
\hline & Sem dor no momento \\
\hline & A dor é leve nesse momento \\
\hline & A dor é moderada nesse momento \\
\hline & A dor é mais ou menos intensa nesse momento \\
\hline & A dor é muito forte nesse momento \\
\hline
\end{tabular}

Seção 2: Cuidados pessoais (Vestir-se, tomar banho etc)

\begin{tabular}{|l|l|}
\hline & Eu posso cuidar de mim sem provocar dor extra \\
\hline & Posso me cuidar mas me causa dor \\
\hline & É doloroso me cuidar e sou lento e cuidadoso \\
\hline & Preciso de alguma ajuda, mas dou conta de me cuidar \\
\hline & Preciso de ajuda em todos os aspectos para cuidar de mim \\
\hline & Eu não me visto, tomo banho com dificuldade e fico na cama. \\
\hline Seção 3: Pesos \\
\hline
\end{tabular}




\begin{tabular}{|l|l|}
\hline & Se levantar coisas pesadas sinto dor extra \\
\hline & $\begin{array}{l}\text { A dor me impede de levantar coisas pesadas, mas dou um jeito, se estão bem } \\
\text { posicionadas, e.g., numa mesa. }\end{array}$ \\
\hline & A dor me impede de levantar coisas pesadas mas dou um jeito de levantar coisas \\
\hline & leves ou pouco pesadas se estiverem bem posicionadas. \\
\hline & Só posso levantar coisas muito leve \\
\hline
\end{tabular}

Seção 4: Andar

\begin{tabular}{|l|l|}
\hline & A dor não me impede de andar (qualquer distância) \\
\hline & A dor me impede de andar mais que $2 \mathrm{Km}$ \\
\hline & A dor me impede de andar mais que $1 \mathrm{Km}$ \\
\hline & A dor me impede de andar mais que poucos metros \\
\hline & Só posso andar com bengala ou muleta \\
\hline & Fico na cama a maior parte do tempo e tenho que arrastar para o banheiro \\
\hline
\end{tabular}

Seção 5: Sentar

\begin{tabular}{|l|l|}
\hline & Posso sentar em qualquer tipo de cadeira pelo tempo que quiser \\
\hline & Posso sentar em minha cadeira favorita pelo tempo que quiser \\
\hline & A dor me impede de sentar por mais de 1 hora \\
\hline & A dor me impede de sentar por mais de 0,5 hora \\
\hline & A dor me impede de sentar por mais que 10 minutos \\
\hline & A dor me impede de sentar \\
\hline
\end{tabular}

\section{Seção 6- De pé}

\begin{tabular}{|l|l|}
\hline & Posso ficar de pé pelo tempo que quiser sem dor extra \\
\hline & Posso ficar de pé pelo tempo que quiser, mas sinto um pouco de dor \\
\hline & A dor me impede de ficar de pé por mais de $1 \mathrm{~h}$ \\
\hline & A dor me impede de ficar de pé por mais 0,5 hora \\
\hline & A dor me impede de ficar de pé por mais de 10 minutos \\
\hline & A dor me impede de ficar de pé \\
\hline
\end{tabular}

\section{Seção 7: Sono}

\begin{tabular}{|l|l|}
\hline & Meu sono não é perturbado por dor \\
\hline & Algumas vezes meu sono é perturbado por dor \\
\hline
\end{tabular}




\begin{tabular}{|l|l|}
\hline & Por causa da dor durmo menos de 6 horas \\
\hline & Por causa da dor durmo menos de 4 horas \\
\hline & Por causa da dor durmo menos de 2 horas \\
\hline & A dor me impede de dormir. \\
\hline
\end{tabular}

Seção 8: Vida sexual (se aplicável)

\begin{tabular}{|l|l|}
\hline & Minha vida sexual é normal e não me causa dor extra \\
\hline & Minha vida sexual é normal, mas me causa dor extra \\
\hline & Minha vida sexual é quase normal, mas é muito dolorosa \\
\hline & Minha vida sexual é muito restringida devido à dor \\
\hline & Minha vida sexual é praticamente inexistente devido à dor. \\
\hline & A dor me impede de ter atividade sexual. \\
\hline
\end{tabular}

\section{Seção 9: vida social}

\begin{tabular}{|l|l|}
\hline & Minha vida social é normal e eu não sinto dor extra \\
\hline & Minha vida social é normal, mas aumenta o grau de minha dor. \\
\hline & $\begin{array}{l}\text { A dor não altera minha vida social, exceto por impedir que faça atividades de } \\
\text { esforço, como esportes, etc }\end{array}$ \\
\hline & A dor restringiu minha vida social e eu não saio muito de casa \\
\hline & A dor restringiu minha vida social a minha casa \\
\hline & Não tenho vida social devido a minha dor \\
\hline
\end{tabular}

\section{Seção 10: Viagens}

\begin{tabular}{|l|l|}
\hline & Posso viajar para qualquer lugar sem dor. \\
\hline & Posso viajar para qualquer lugar, mas sinto dor extra \\
\hline & A dor é ruim, mas posso viajar por 2 horas \\
\hline & A dor restringe minhas viagens para distâncias menores que1 hora \\
\hline & A dor restringe minhas viagens para as necessárias e menores de 30 minutos \\
\hline & A dor me impede de viajar, exceto para ser tratado. \\
\hline
\end{tabular}

Para cada seção de seis afirmações o ponto total é 5 . Se a primeira afirmação é marcada, o ponto é 0 . Se for o último, o ponto é 5 . As afirmações intermediárias são pontuadas de acordo com este ranking. Se mais que uma afirmação for assinalada em cada seção, escolha 
o maior ponto. Se todas as 10 seções forem completadas a pontuação é calculada da seguinte maneira: Se 16 pontos foi o ponto total sendo que são 50 os pontos possíveis, $16 / 50 \times 100=32 \%$. Se uma seção não for marcada ou não se aplica a pontuação é calculada da seguinte maneira, de acordo com o exemplo de pontuação máxima de 16: 16/40 X100= 35,5\%. O autor recomenda arredondar a porcentagem para um número inteiro. 